\title{
A Cooling Vest for Working Comfortably in a Moderately Hot Environment
}

\author{
Naoe Nishihara ${ }^{1)}$, Shin-ichi Tanabe ${ }^{2)}$, Hirofumi Hayama ${ }^{3)}$, and Masayoshi Komatsu ${ }^{4)}$ \\ 1) Department of Human Environmental Engineering, Ochanomizu University \\ 2) Department of Architecture, Waseda University \\ 3) Graduate School of Engineering, Hokkaido University \\ 4) NTT FACILITIES
}

\begin{abstract}
To alleviate worker's thermal discomfort in a moderately hot environment, a new cooling vest was designed and proposed in this paper. To investigate the effect of the cooling vest and to collect the knowledge for the design of comfortable cooling vest, subjective experiments were conducted. Two kinds of cooling vests, the new one and the commercially available one, were used for comparison. The new cooling vest had more insulation and its surface temperature was higher than the commercially available one. Experiments were performed in the climatic chamber where operative temperature was controlled at $30.2^{\circ} \mathrm{C}$ and relative humidity was at $37 \%$ under still air. In addition, experiment without cooling vest was carried out as a control condition. The results obtained in these experiments were as follow: 1) By wearing both types of cooling vest, the whole body thermal sensation was closer to the neutral conditions than those without cooling vest. This effect was estimated to be equal to the $5.7^{\circ} \mathrm{C}$ decrement of operative temperature. The subjects felt more comfortable with the cooling vest than without it. They felt more thermally acceptable than that without cooling vest. Wearing the cooling vest was useful to decrease the sweating sensation. 2) The local discomfort was observed when the local thermal sensation was "cool" " cold" with the cooling vest. 3) The new cooling vest kept the skin temperature at chest at about $32.6^{\circ} \mathrm{C}$. On the other hand, by wearing the commercially available one, it lowered to about $31.1^{\circ} \mathrm{C}$. By wearing the new cooling vest, there was a tendency that local thermal sensation vote was higher and local comfort sensation vote was more comfortable than those of the condition wearing the commercially available one. It is important for the design of a comfortable cooling garment to prevent over-cool down from the body. J Physiol Anthropol 21 (1): 75-82, 2002 http://www.jstage.jst.go.jp/en/
\end{abstract}

Keywords: cooling vest, thermal sensation, thermal comfort, climatic chamber, subjective experiment

\section{Introduction}

Recent improvements in the hardware performance of telecommunication machines have allowed higher air temperature atmosphere with less air-conditioning energy in the machine room. However, workers in the maintenance section may feel thermal discomfort and it may reduce their work productivity. In the telecommunication machine room, the workers must wear long-sleeved shirts for security and dust control, so it is difficult to thermoregulate by reducing clothing insulation.

To alleviate worker's thermal discomfort in such a moderately hot environment, a new cooling vest was developed and tested in this paper. The cooling vest has cooling function in clothing itself. Clothing is namely the closest external environment of human being. Because this system allows to cool down human body directly and to control individually, it may be the most energy efficient way of cooling. In this study, we designed the ice-bag vest, which cooled on trunk.

Previous studies of the cooling garment pointed out that it was useful in alleviating thermal physiological stress (Bishop et al., 1988; Duncan and Konz, 1978; Pimental et al., 1987; Hayashi and Tokura, 2000). The cooling garment was mainly for workers in extreme hot environment such as soldiers, astronauts or workers wearing nuclear, biological, and chemical protective clothing. Since these cases dealt with human lives and health, the main purpose of these studies was whether the cooling garment alleviated heat stress efficiently.

The purpose of this study is to develop a cooling vest 
used in a moderately hot environment and to evaluate thermal comfort by wearing it. In a moderately hot environment, it is necessary not only to alleviate heat stress but also to consider thermal comfort of the wearer. To investigate the effect of the cooling vest and to collect the knowledge for the design of a comfortable cooling vest, subjective experiments were conducted in a climatic chamber. Two kinds of cooling vests, the new one developed in this study and the commercially available one, were used for comparison.

\section{Materials}

Cooling region and methods of cooling vest

From literature survey, even if the mean skin temperature was similar, the sensations were different depending on the body segments (Hanada, 1982). Since the density of cold receptors on trunk is greater, its sensitivity is also higher (Lee and Tamura, 1995a, b). Cold stimuli on trunk affect more thermal sensation than that of the extremities (Maruyama and Tamura, 1989). Shvartz et al. (1974) reported that cooling of the chest or back had the advantage of a direct effect on the heart area and a relatively large surface area cooled. Based on these literature surveys, we designed a cooling vest that cooled down on the trunk. As cooling methods, there are watercooled, air-cooled, ice bag, and fan systems in existing cooling garment. We chose the ice pack system because it was not required to carry mechanical devices, so it may not disturb worker's performance. Epstein et al. (1986) described ice bag vest had the highest cooling capacity among them on the physiological status. Konz (1984) pointed out the advantages of ice bag system as follows: it has high latent heat of melting, it changes phase at a temperature well below skin temperature (but not so low as to cause skin injury), it is readily available and inexpensive, it is not harmful and does not irritate the skin, it is easily and rapidly refrozen, and it is easy to incorporate into a garment.

The thermal comfort of cooling vests, which had ice bags and cool down on the trunk, was evaluated in this study.

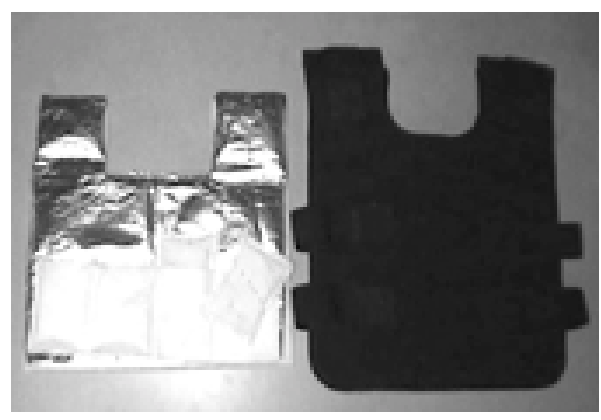

Fig. 1 Comfort Vest I.

\section{Cooling vest}

We used the two types of the cooling vest for comparison. One was the cooling vest developed and named "Comfort Vest I" in this study. The other was a commercially available cooling vest "Type I" that was developed by an American company.

"Comfort Vest I" is shown in Fig. 1. The prototypecooling vest had a cooling effect for only 40 minutes (Tanabe et al., 2000). We improved its performance. The quantity of ice bag was doubled and it was redesigned to fit body. This improved cooling vest was named "Comfort Vest I". Properties of the fabric of the cooling vest are shown in Table 1. Sixteen small ice bags were used for the present vest. Distribution of ice bags is illustrated in Fig. 2. Melting point of the ice bag was $-1^{\circ} \mathrm{C}$, and the latent heat of phase change was $3.4 \times 10^{5} \mathrm{~J} / \mathrm{kg}$, which is indicated by the manufacture's specification. Six ice bags $(120 \mathrm{~g} /$ each bag) at chest and ten ice bags $(100 \mathrm{~g} /$ each bag) at back were distributed. The cooling area was about $5.7 \times 10^{-2} \mathrm{~m}^{2}$ at chest and $7.7 \times 10^{-2} \mathrm{~m}^{2}$ at back. The total weight of this cooling vest was $2,114 \mathrm{~g}$. The cooling packs were insulated with four layers of aluminum, styrene sheet, vinyl sheet, and water absorptive non-woven fabric. The layer of non-woven fabric was useful to absorb the condensation on the cooling packs.

"Type I" is shown in Fig. 3. "Type I" has the cooling packs in its garment at the back and chest. The chemical composition of this cooling pack was hexadecane (88.6\%), tetradecane (9.4\%), and octadecane (2.0\%). Regarding melting temperature, the onset temperature was $10.2^{\circ} \mathrm{C}$

Table 1 Properties of the fabric of the cooling vest

\begin{tabular}{lccccc}
\hline & $\begin{array}{c}\text { Water Absorption } \\
(\mathrm{mm})\end{array}$ & $\begin{array}{c}\text { Air Permeability } \\
\left(\mathrm{cm}^{3} / \mathrm{cm}^{2} / \mathrm{s}\right)\end{array}$ & $\begin{array}{c}\text { Dryness } \\
(\mathrm{min})\end{array}$ & $\begin{array}{c}\text { Water Vapor Resistance }^{\star 4} \\
\left(\mathrm{~g} / \mathrm{m}^{2} / \mathrm{h}\right)\end{array}$ \\
\hline Type I & Direction of warp & Direction of weft & & & 243 \\
Comfort Vest I & 1 & 1 & 5.6 & 255 & 304 \\
\hline
\end{tabular}

*1 JIS L 1096 6.26.1 B, *2 JIS L 1096 6.27.1 A. *3 It was measured in accordance with JIS L 1096 6.25.1 A. Because of fabric size’s limit, $20 \times 20 \mathrm{~cm}$ sample was used in the stead of using $40 \times 40 \mathrm{~cm}$ one. * 4 JIS L $1099 \mathrm{~A}-1$. 


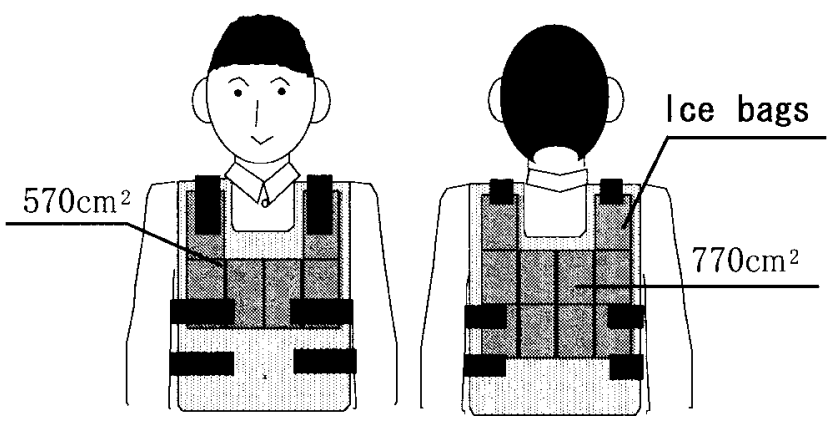

Fig. 2 Distribution of ice bags.

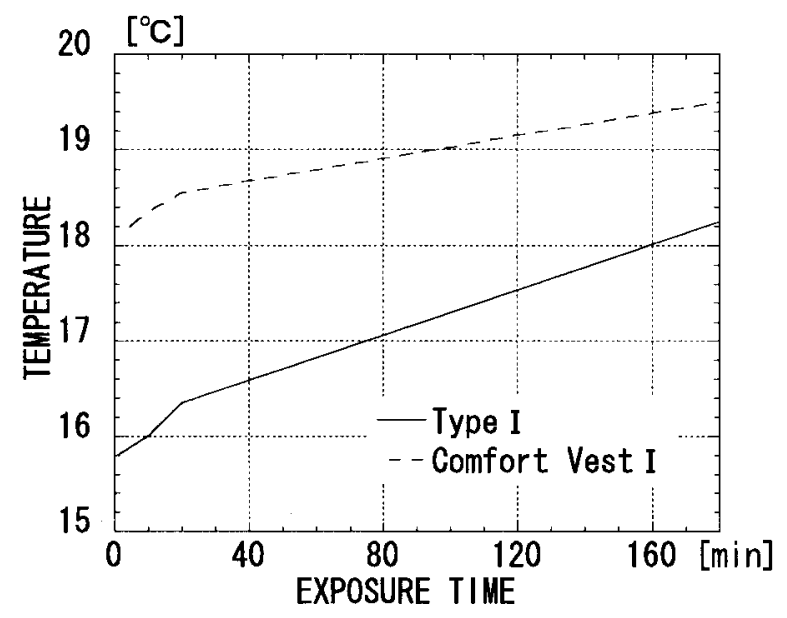

Fig. 4 The surface temperature of cooling vests.

and the peak temperature was $17.4^{\circ} \mathrm{C}$. "Type I" has no insulation between the pack and the wearer. The cooling area was about $7.9 \times 10^{-2} \mathrm{~m}^{2}$ at chest and back, respectively. The total weight of "Type I" was $1,755 \mathrm{~g}$.

The surface temperatures of the cooling vest on body side were measured with Copper - Constantan thermocouples. The cooling vests were worn upon the thermal manikin (Tanabe and Hasebe, 1993) including a working uniform. The measurements were conducted after the thermal manikin was reached to the thermal steady state at operative temperature of $25^{\circ} \mathrm{C}$. This method took no account of the latent heat transfer. Comparison of the two surface temperatures is shown in Fig. 4. The average surface temperature of the cooling vest (1-90 min) was $16.8^{\circ} \mathrm{C}$ for "Type I" and $18.8^{\circ} \mathrm{C}$ for "Comfort Vest I".

\section{Experimental Procedure}

Subjective experiments were conducted to evaluate the effect of the cooling vest in a climatic chamber at the Ochanomizu University during August in 1997. The plan of the chamber and experimental set up are shown in Fig.

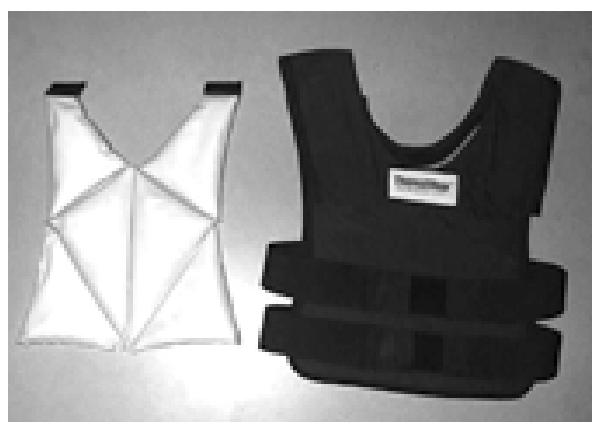

Fig. 3 Type I.

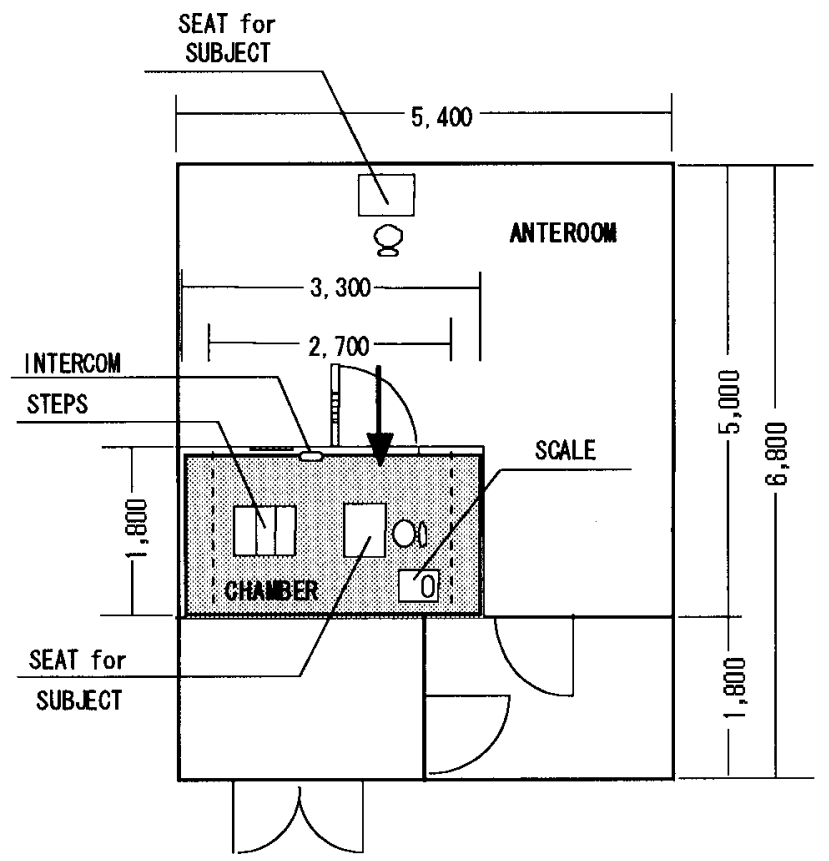

Fig. 5 Plan and experimental setup in a climatic chamber.

5.

Four college-age male subjects participated in the wear trial test. All subjects were volunteers, who were paid for participating in the experiments. Anthropometric data for the subjects are listed in Table 2. Experiments were performed with 2 kinds of cooling vests (Comfort Vest I and Type I). In addition, experiment without cooling vest was carried out as a control condition. The subjects wore working clothes, which were consisted of their own undershorts, a long sleeve shirt, a cotton T-shirt, trousers, and socks. This clothing ensemble was estimated as 0.88 clo by measurement with thermal manikin. The cooling vest was worn on the working clothes.

Experimental procedure is shown in Fig. 6. Each subject was staying in the anteroom for ten minutes (sedentary activity), and then he entered into the 
Table 2 Anthropometric data for the subjects

( ) Standard Deviation

\begin{tabular}{ccccccc}
\hline Sex & Number & $\begin{array}{c}\text { Age } \\
{[\text { year }]}\end{array}$ & $\begin{array}{c}\text { Height } \\
{[\mathrm{cm}]}\end{array}$ & $\begin{array}{c}\text { Weight } \\
{[\mathrm{kg}]}\end{array}$ & $\begin{array}{c}\text { Body Surface Area } \\
{\left[\mathrm{m}^{2}\right]}\end{array}$ & Rohrer Index $^{* 6}$ \\
\hline Male & 4 & 22.3 & 168.8 & 68.5 & 1.80 & 143.3 \\
& $(3.4)$ & $(2.99)$ & $(9.22)$ & $(0.09)$ & $(24.1)$ \\
\hline
\end{tabular}

*5 Calculated by Takahira's Equation: $\mathrm{A}=72.46 \mathrm{~W}^{0.425} \times \mathrm{H}^{0.725}$. ${ }^{*} 6$ Rohrer Index $=\mathrm{W} / \mathrm{H}^{3} \times 10^{7}$.

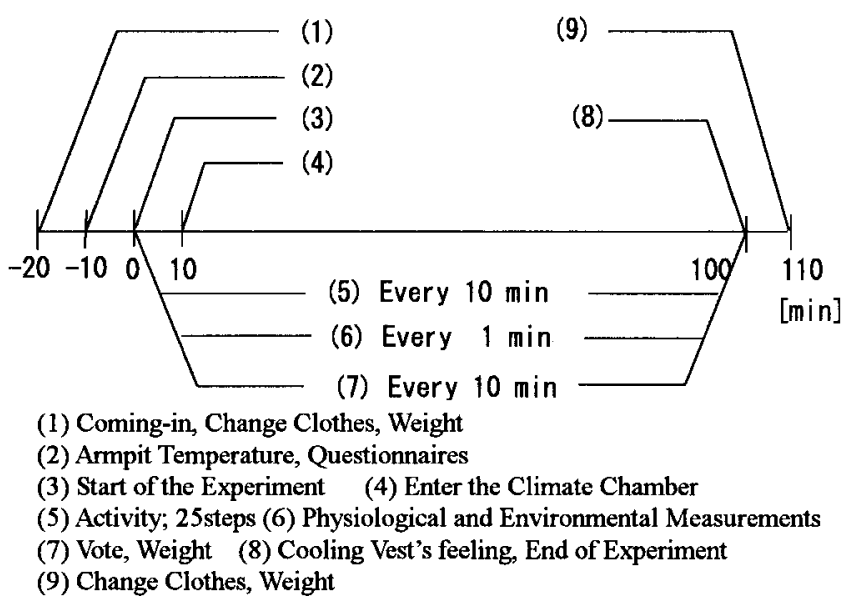

Fig. 6 Experimental procedure.

chamber. The anteroom was conditioned at an operative temperature of $24.5^{\circ} \mathrm{C}$, relative humidity of $54 \% \mathrm{RH}$, and still air. The chamber was conditioned at an operative temperature of $30.2^{\circ} \mathrm{C}$, relative humidity of $37 \% \mathrm{RH}$, and still air. Each subject was asked to go up and down 25 steps each 10-minute during the 90-minute experimental session. During the intermittent period, the subject was kept at sedentary activity. This activity was estimated at 1.4 met (Tanabe et al., 1995). They were allowed to drink water as much as they desired. However, consumption of water by each subject was precisely recorded. No food was permitted to consume during the experimental session.

Skin temperatures on the chest and back were measured. Temperature and relative humidity under clothing at chest and back were also measured at $3 \mathrm{~mm}$ above the skin. These were recorded every 1 min during the experimental period. Skin wettedness was calculated from skin temperature, temperature under clothing, and relative humidity there (Berglund et al., 1985). Subjects voted their thermal sensation, comfort sensation, thermal acceptability, and sweating sensation every 10-min during the experimental period. They were also asked their body parts desired to be cool. The part of voting scale is shown in Fig. 7. Overall feeling for cooling vest was also asked.

The data during 20-90 min was used for calculation of

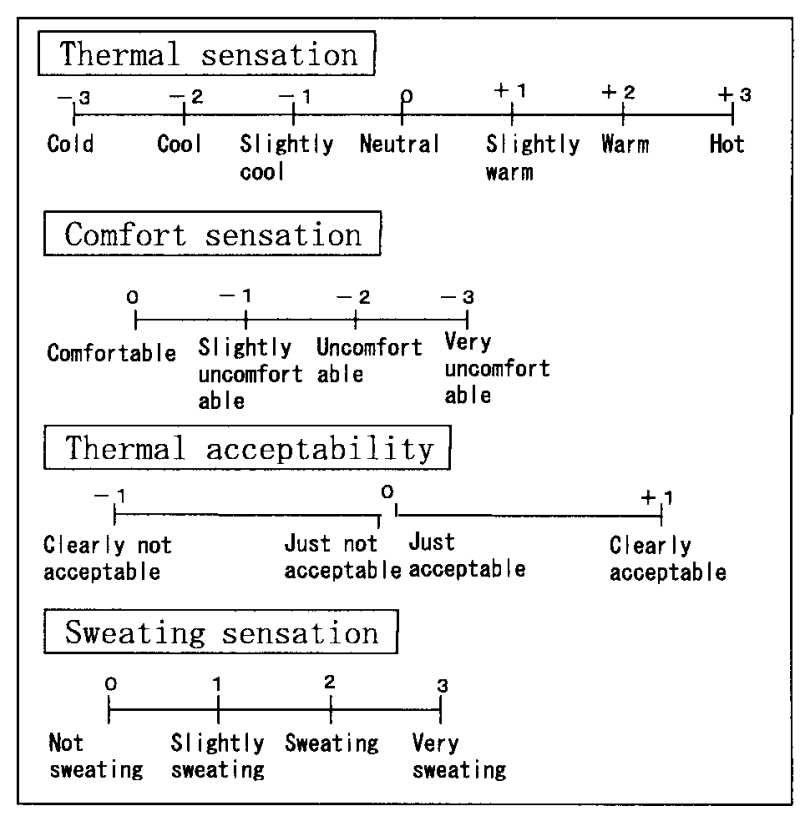

Fig. 7 Voting sheet.

mean values. The differences of mean values among the experimental conditions (Control, Type I, and Comfort Vest I) were analyzed using one-way ANOVA. When a statistically significant result was found, post hoc comparisons were made using Fisher's protected least significant difference procedure. The level of significance was set at $p<0.05$.

\section{Results}

\section{Whole body reaction}

The results of whole body thermal sensation vote are shown in Fig. 8. The average for [Control] during 20-90 min was 1.36. On the other hand, with cooling vest, the figure was significantly lower and closer to the neutral conditions than that with the control condition $(\mathrm{p}<0.01)$. The average for [Type I] and [Comfort Vest I] during 2090 min was 0.28 and 0.25 , respectively. The conversion of the cooling performance of the cooling vests into the operative temperature was calculated by using PMV (ISO7730, 1993) in the condition of 0.88 clo and 1.4 met. They were estimated to be equal to around $5.7^{\circ} \mathrm{C}$ decrement of operative temperature. 


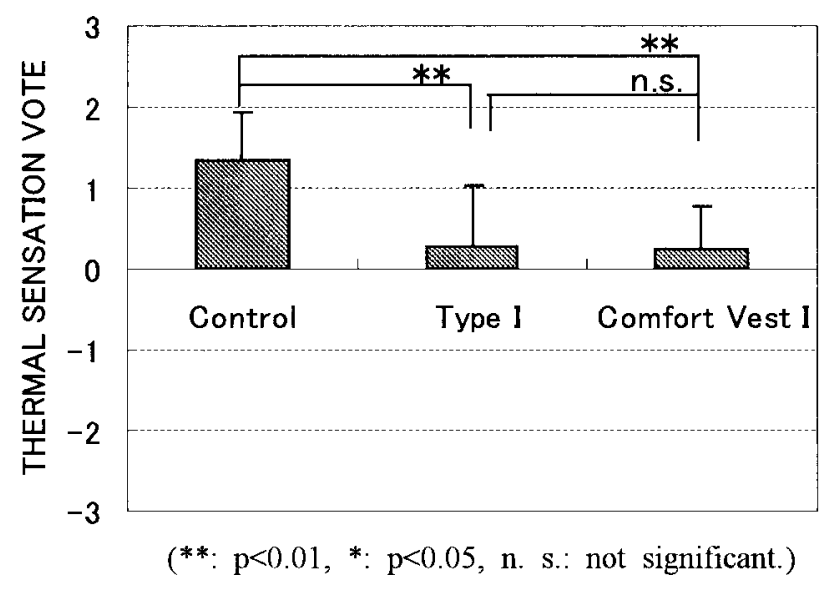

Fig. 8 Whole body thermal sensation vote.

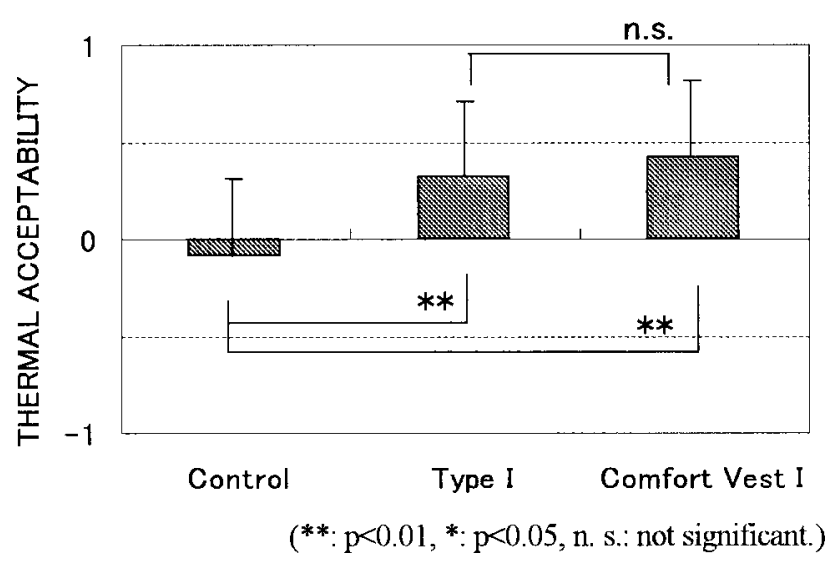

Fig. 10 Thermal acceptability.

The results of whole body comfort sensation vote are shown in Fig. 9. The average for [Control] during 20-90 min was -1.16 . On the other hand, with cooling vest, the figure was significantly closer to the neutral conditions than that with the control condition $(p<0.01)$. The average for [Type I] and [Comfort Vest I] during 20-90 min was -0.49 and -0.34 , respectively. The conversion of the cooling performance of the cooling vests into the operative temperature was calculated by using DISC (ASHRAE, 1997) in condition of 0.88 clo and 1.4 met. They were estimated to be equal to around $2.7^{\circ} \mathrm{C}$ for [Type I] and $3.8^{\circ} \mathrm{C}$ for [Comfort Vest I] decrement of operative temperature.

The results of thermal acceptability are shown in Fig. 10. The average for [Control] during 20-90 min was 0.08 . On the other hand, with cooling vest, those values became positive value, which meant "acceptable". The average for [Type I] and [Comfort Vest I] during 20-90 min was 0.32 and 0.43 , respectively.

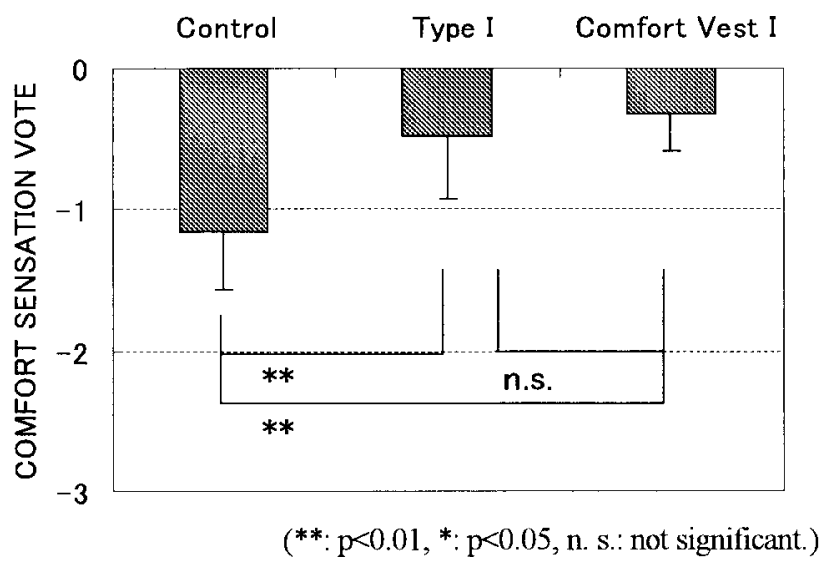

Fig. 9 Whole body comfort sensation vote.

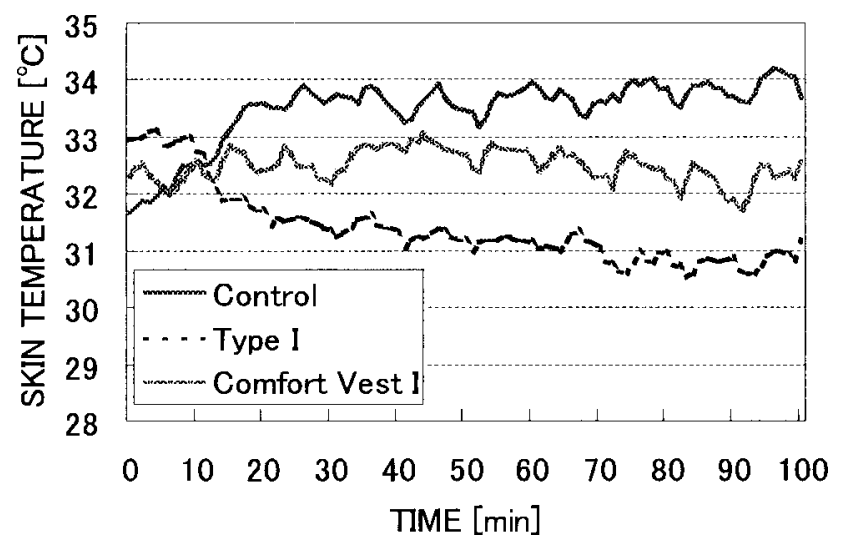

Fig. 11 The skin temperature at chest.

\section{Local body reaction at cooling part}

The skin temperature at chest is shown in Fig. 11. The skin temperature at chest rose up to about $33.7^{\circ} \mathrm{C}$ for control condition. By wearing Comfort Vest I, the value was kept almost the same level as in the anteroom where air- conditioned room was simulated without the cooling vest. The average value of [Comfort Vest I] during 20-90 min was $32.6^{\circ} \mathrm{C}$. However, by wearing Type I, they lowered to about $31.1^{\circ} \mathrm{C}$.

The results of local thermal sensation vote at chest are shown in Fig. 12. The average for [Control] during 20-90 min was 1.10 . With cooling vest, the value was significantly lower than that with control condition. The average for [Type I] and [Comfort Vest I] during 20-90 min was -1.55 and -1.26 , respectively. There was a tendency that local thermal sensation vote of [Type I] was lower than that of [Comfort Vest I] $(\mathrm{p}<0.1)$.

The results of local comfort sensation vote at chest are shown in Fig. 13. The average for [Control] during 20-90 min was -1.01 . With cooling vest, the value was significantly closer to the thermal neutrality than that 


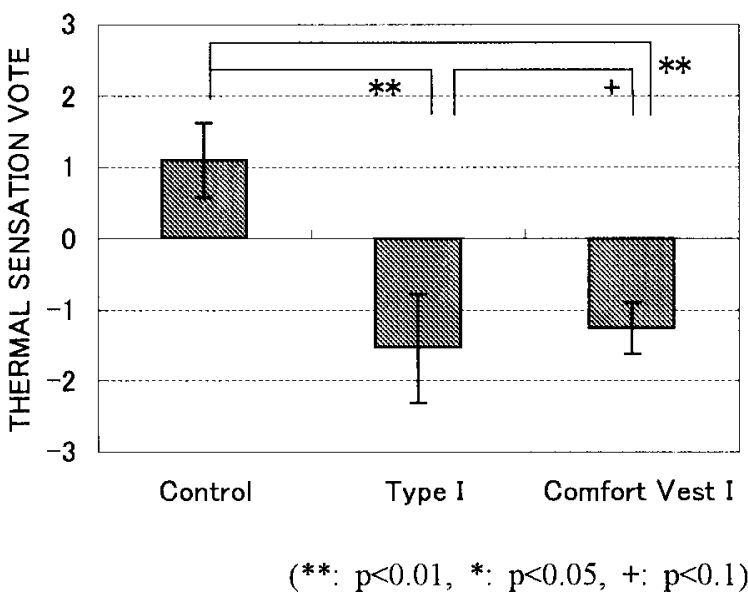

Fig. 12 Local thermal sensation vote at chest.

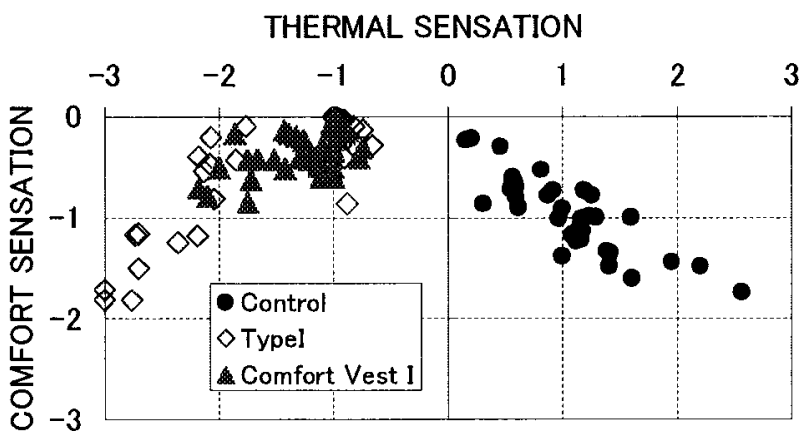

Fig. 14 The relationship between local thermal sensation vote and local comfort sensation vote at chest.

with control condition. The average for [Type I] and [Comfort Vest I] during 20-90 min was -0.52 and -0.33 , respectively. Between two types of cooling vest, there was a tendency that local comfort sensation vote of [Type I] was more uncomfortable than that of [Comfort Vest I] $(\mathrm{p}<0.1)$.

The relationship between local thermal sensation vote and local comfort sensation vote at chest is shown in Fig. 14. By wearing the cooling vest, the data of local thermal sensation vote were distributed on the negative side, which meant that the subjects felt cool. The more the thermal sensation vote deviated from thermal neutrality, the more the subjects felt uncomfortable. Especially, wearing [Type I] made local thermal sensation lower and caused more local discomfort than wearing [Comfort Vest I].

\section{Skin wettedness and sweating sensation}

The skin wettedness at chest is shown in Fig. 15. In the early stage of wearing the cooling vest, the skin wettedness was lower than that with the control

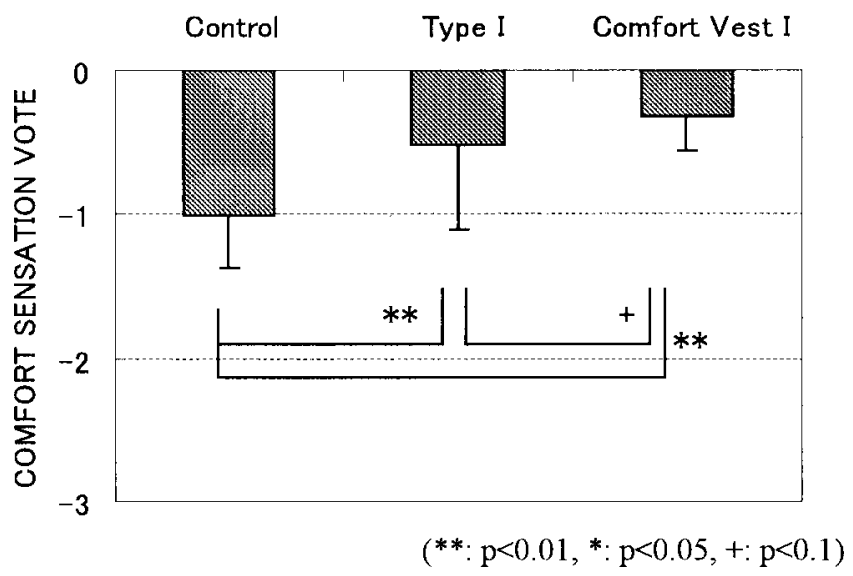

Fig. 13 Local comfort sensation vote at chest.

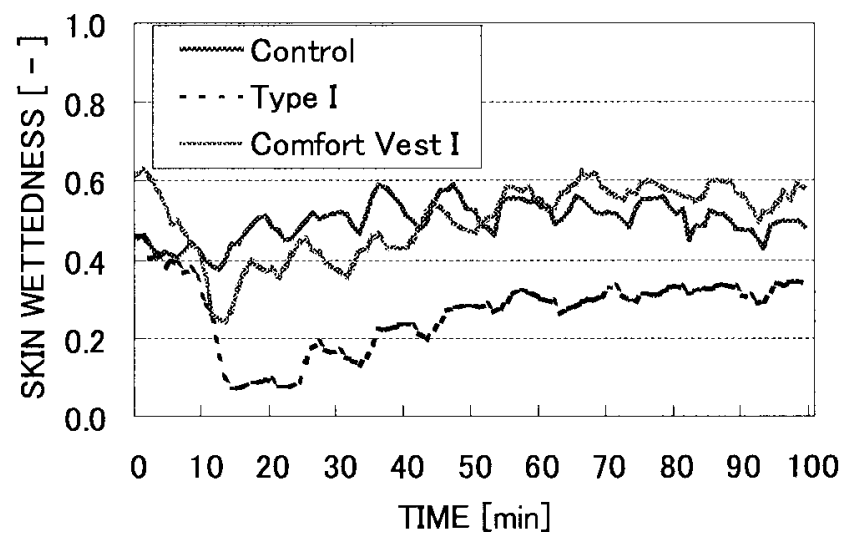

Fig. 15 Skin wettedness at chest.

condition. However, the skin wettedness with the cooling vest increased gradually. About [Type I], it was significantly lower than that of the control condition. There was no significant difference of the skin wettedness between [Comfort Vest I] and [Control].

The results of sweating sensation vote are shown in Fig. 16. The average during 20-90 min was 1.02 in [Control], 0.21 in [Type I] and 0.26 in [Comfort Vest I]. The sweating sensation vote with the cooling vest was significantly lower than that of the control condition. Wearing the cooling vest was useful to decrease the sweating sensation.

\section{Discussion}

To investigate the effect of the cooling vest and to collect the information about the design of comfortable cooling vest, subjective experiment was conducted. Two types of the cooling vest were used in this experiment; one was the new cooling vest "Comfort Vest I" that was 


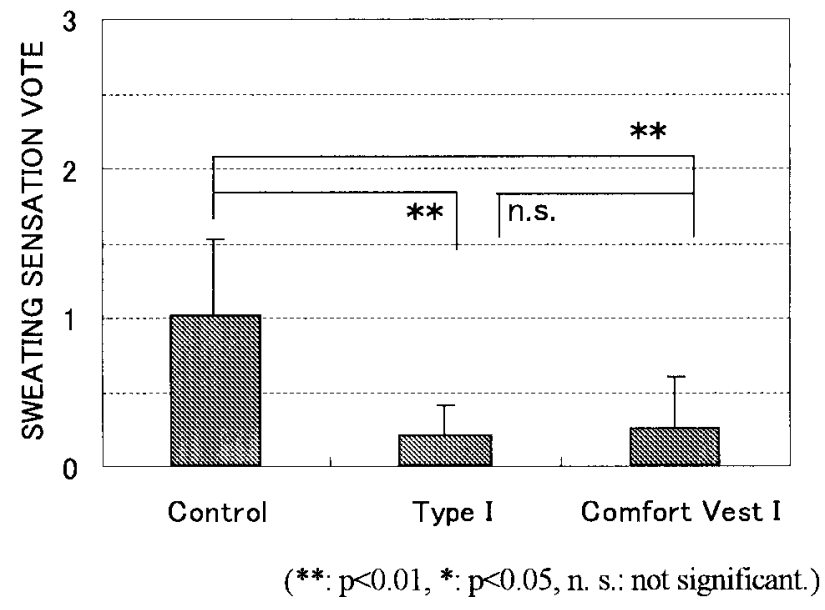

Fig. 16 Sweating sensation vote.

designed in the present study, and the other was "Type I" that was a commercial product. "Comfort Vest I" had more insulation and its surface temperature was higher than "Type I".

By wearing both types of the cooling vest, there were some cooling effects on thermal, comfort, and sweating sensation votes, and thermal acceptability. With the cooling vest, whole body thermal and comfort sensation votes were significantly closer to the neutral conditions than that under the control condition. Also, by wearing the cooling vest, even the warm environment was felt more thermally acceptable. From the whole body thermal sensation votes, the effect of these cooling vests was estimated to be equal to about $5.7^{\circ} \mathrm{C}$ decrement of operative temperature. From the whole body comfort sensation votes, the effect of [Type I] and [Comfort Vest I] was estimated to be equal to $2.7^{\circ} \mathrm{C}$ and $3.8^{\circ} \mathrm{C}$ decrement of operative temperature respectively.

The local thermal sensation deviating from the neutral condition resulted in the local discomfort of cooling part. The local discomfort sensation was under -1 when the local thermal sensation vote was under -2 with the cooling vest.

The skin wettedness with the cooling vest increased gradually. It may be because that wearing cooling vests made skin temperature lower and that evaporative cooling capacity decreased. On the other hand, the sweating sensation vote with the cooling vest was significantly lower than that under the control condition. Wearing the cooling vest was useful to decrease the sweating sensation.

Between the types of cooling vest, there was a tendency that local thermal sensation vote of [Type I] was lower than [Comfort Vest I] $(\mathrm{p}<0.1)$. Also, there was a tendency that local comfort sensation vote of [Type I] was more uncomfortable than that of [Comfort Vest I] $(p<0.1)$. These results may be caused by that "Type I" had low insulations and its surface temperature was lower than that of "Comfort Vest I". It made the skin temperature at the cooling part with "Type I" lower than with "Comfort Vest I". Excess in cooling might cause local thermal discomfort.

"Comfort Vest I" kept the skin temperature higher than that of "Type I". However, "Comfort Vest I" was as the same level as "Type I" at cooling effect of the whole body thermal, whole body comfort, sweating sensation, and thermal acceptability. "Comfort Vest I" could prevent over-cool down from the body, and that resulted in avoiding the local thermal discomfort.

By wearing the cooling vest, whole body thermal sensation came close to thermal neutrality and whole body thermal discomfort was alleviated in a moderately hot working environment. However, excess in cooling resulted in local thermal discomfort in this study. McIntyre (1980), Olesen (1985), Berglund (1988), Parsons (1993) and ISO 7730 (1993) discussed thermal local discomfort when whole body was in neutral condition. They reported that the condition for thermal comfort is that there must be no local thermal discomfort, in addition to three conditions proposed by Fanger (1972): heat balance; sweat rate within comfort limits; and mean skin temperature within comfort limits. Although the case in which the cooling vest was used differs from the neutral condition, it is important for the design of the comfortable cooling garment not only to alleviate heat stress but also to prevent over-cool down from the body.

Acknowledgement The authors wish to express their appreciation to Ms. R. Takaki for her assistance during the experiments.

\section{References}

ASHRAE Handbook FUNDAMENTALS (1997)

Berglund LG, Oohori T, Cunningham DJ, Gagge AP (1985) Vapor resistance of clothing, Local skin wettedness, and discomfort. ASHRAE Transactions 91: 3-12

Berglund LG (1988) Thermal Comfort: A review of some recent research. In Mekjavic IB, Banisterand EW, Morrison JB eds. Environmental ergonomics. Taylor \& Francis, London, 70-86

Bishop PA, Nunneley SA, Garza JR, Constable SH (1988) Comparisons of air vs. liquid microenvironmental cooling for persons performing work while wearing protective clothing. Trends in ergonomics/human factorsV, Elsevier Science Publishers, Amsterdam, 433440

Duncan JR, Konz SA (1978) Industrial and laboratory evaluations of personal dry-ice cooling. AIIE Transactions 10: 131-138 
Epstein Y, Shapiro Y, Brill S (1986) Comparison between different auxiliary cooling devices in a severe hot/dry climate. Ergonomics 29: 41-48

Fanger PO (1972) Thermal comfort. McGraw-Hill, New York: $19-67$

Hanada K, Mihira K, Kamisasa H (1982) The effect of unevenly distributed thermal stimuli on the sensation of warmth and coolness. Applied Ergonomics 13: 49-53

Hayashi C, Tokura H (2000) Improvement of thermophysiological stress in participants wearing protective clothing for spraying pesticide, and its application in the field. Int Arch Occup Environ Health 73: $187-194$

ISO-7730 (1993) Moderate thermal environmentsDetermination of the PMV and PPD indices and specification of the conditions for thermal comfort

Konz SA (1984) Personal cooling garments-a review. ASHRAE Trans 90: 499-517

Lee U, Tamura T (1995a) Thermal spot over human body surface (Part I), Regional difference in cold spot distribution. Ningen To Seikatsukankyo (J. Human and Living Environment) 2: 30-36 (in Japanese)

Lee U, Tamura T (1995b) Distribution of cold sensitivity over human skin. Nihon Kasei Gakkaishi (Journal of home economics of Japan) 46: 1081-1090 (in Japanese)

Maruyama Y, Tamura T (1989) Responses of skin temperature and thermal sensation to unevenly distributed thermal stimuli. Nihon Seikisho Gakkai Zasshi (Jpn. J. Biometeor.) 26: 143-154 (in Japanese)

McIntyre DA (1980) Indoor climate. Applied Science Publisher, London, 380-383

Olesen BW (1985) Local thermal discomfort. Bruel and Kjar Technical Review No. 1, Copenhagen

Parsons KC (1993) Human thermal environments. Taylor \& Francis, London, 150
Pimental NA, Cosimini HM, Sawka MN, Wenger CB (1987) Effectiveness of an air cooled vest using selected air temperature and humidity combinations. Aviation, Space, and Environmental Medicine 58: 19-24

Shvartz E, Aldjem M, Ben-Mordechai J, Shapiro Y (1974) Objective approach to a design of a whole-body, watercooled suit. Aerospace Medicine 45: 711-715

Tanabe S, Hasebe Y (1993) Evaluation of thermal environments with a skin-surface-temperaturecontrolled thermal manikin. Nihon Kenchiku Gakkai Keikakukei Ronbun Houkokusyu (Journal of Architecture, Planning and Environmental Engineering) 448: 1-8 (in Japanese)

Tanabe S, Imamura H, Shou S, Suzuki T (1995) Effects of humidity on thermal comfort in office space (Part 3 Experimental methods and subjective experimental results for cotton and polyester clothing ensembles). Kuuki Tyowa Eisei Kougakkai Gakujutsu Kouenkai Kouen Ronbunsyu (Proc. of annual conference of SHASE) 685-688 (in Japanese)

Tanabe S, Nishihara N, Hasebe Y, Hayama H, Komatsu M (2000) The cooling vest for comfortable work environment in the telecommunication machine room. Kuuki Tyowa Kutyo Kougakkai Ronbunsyu (Transactions of the society of heating, air-conditioning and sanitary engineers of Japan) 79:61-70 (in Japanese)

Received: August 2, 2001

Accepted: December 5, 2001

Correspondence to: Naoe Nishihara, Tanabe Laboratory, Department of Architecture, Waseda University, 55-N701, 3-4-1 Okubo, Shinjuku-ku, Tokyo 169-8555, Japan e-mail: nishihara@tanabe.arch.waseda.ac.jp 